Check for updates

Cite this: RSC Adv., 2017, 7, 24462

\title{
Synthesis and characterisation of push-pull flavin dyes with efficient second harmonic generation (SHG) properties $\uparrow$
}

\author{
Nabeel Mohammed, $\dot{\ddagger}^{\mathrm{a}}$ Alan A. Wiles, (I) $\dot{\ddagger}^{\mathrm{a}}$ Michael Belsley, (D) $\dot{\dagger}^{\mathrm{b}}$ Sara S. M. Fernandes, ${ }^{c}$ \\ Michele Cariello, ${ }^{a}$ Vincent M. Rotello, (D) d M. Manuela M. Raposo (D)*c \\ and Graeme Cooke (iD *a
}

\begin{abstract}
Organic compounds displaying second-order non-linear optical properties are key materials for optoelectronics. Here, three push-pull flavin derivates (FLA-A-C) have been synthesised and their optical, redox and second harmonic generation (SHG) properties have been investigated. In particular, we describe the role differing electron donor units ( $N, N$-dimethylaniline-, $N, N$-diphenylaniline- and ferrocenyl-) attached through the $C(8)$ position of the flavin unit have on the optical and redox properties of the latter. HyperRayleigh scattering in dioxane solutions using a fundamental wavelength of $1064 \mathrm{~nm}$ was employed to evaluate their second-order nonlinear optical properties. Our experiments have indicated that their first hyperpolarisabilities $(\beta)$ are influenced by the electronic nature and strength of the donor groups. $N, N-$ dimethylaniline-functionalised derivative FLA-A, exhibited the largest first hyperpolarisability $(\beta=9550 \times$ $10^{-30}$ esu, using the $T$ convention) and high decomposition temperature $\left(T_{d}=312{ }^{\circ} \mathrm{C}\right)$, thus indicating its potential application as a useful material for incorporation into non-linear optical devices.
\end{abstract}

Received 23rd March 2017

Accepted 26th April 2017

DOI: $10.1039 / \mathrm{c} 7 \mathrm{ra} 03400 \mathrm{~h}$

rsc.li/rsc-advances
Organic push-pull NLO chromophores are promising materials, and typically comprise of a strong electron donor (D) (e.g. arylamino groups) and strong electron acceptor (A) group (e.g. cyano, nitro, di- or tricyanovinyl) linked through a $\pi$-bridge (aromatic or heterocyclic) $(\mathrm{D}-\pi-\mathrm{A})$. This $\mathrm{D}-\pi-\mathrm{A}$ arrangement promotes efficient intramolecular charge-transfer (ICT) between the D and A groups and generates dipolar push-pull systems possessing an intense, low-energy CT absorption, and the propensity to display strong molecular SHG. The NLO response correlates strongly with the strength of the attached D and A groups as well as the electronic nature and length of the $\pi$ conjugated spacer. ${ }^{3}$

Amines $\left(\mathrm{NR}_{2}\right)$, such as $4-\mathrm{N}, \mathrm{N}$-dimethylaniline- or $4-\mathrm{N}, \mathrm{N}$ diphenylaniline-, are commonly used donor groups in NLO chromophores. The latter moieties tend to have a lower electron donating ability due to the partial delocalisation of the nitrogen nonbonding lone pair to the conjugated phenyl units that are usually organised in a nonplanar fashion. ${ }^{5}$ On the other hand, $N, N$-diarylaniline moieties usually impart significantly higher thermo- and photostabilities compared to their $\mathrm{N}, \mathrm{N}$-dialkylaniline analogues. Consequently, chromophores featuring $N, N$-dialkylaniline donor groups tend to show much higher nonlinearities compared to their $N, N$-diarylaniline brethren, although they generally have much lower thermostabilities. ${ }^{6}$ Organometallic ${ }^{7}$ groups such as ferrocene have also been utilised as D moieties in NLO chromophores. ${ }^{8}$ More recently, electron-rich (e.g. thiophene and pyrrole) and electron-poor (e.g. azoles and diazines) five-membered heterocycles have also been 
used as efficient "non-conventional" electron donor or acceptor moieties, respectively, due to their auxiliary D-A heterocycle effect. $^{9}$

Flavins are electron deficient heterocycles and are important cofactors in a range of flavoenzymes. ${ }^{10}$ Synthetic flavin derivatives due to their convenient synthesis, photostability and tunable optical and redox properties have found application in a diverse range of areas including: supramolecular chemistry ${ }^{\mathbf{1 1}}$ and photonics such as solvatochromic probes ${ }^{\mathbf{1 2}}$ and photoninduced energy and charge transfer systems. ${ }^{13}$ However, their application as A units in NLO materials has not been widely reported. For example, Stanley and co-workers have reported that a push-pull flavin derivative displayed a hyperpolarisability $\left(\beta_{0}\right)$ of $720 \times 10^{-30}$ esu, estimated with the aid of Stark spectroscopy. ${ }^{\mathbf{1 4}}$

Here we report the synthesis and characterisation of three flavin-based dyes FLA-A-C featuring $N, N$-dimethylaniline-, $N, N$ diphenylaniline- and ferrocenyl-units attached through the $\mathrm{C}(8)$ position of the flavin unit to ensure good electronic communication between the differing $\mathrm{D}$ units and the flavin A moiety. ${ }^{15}$ FLA-C features an acetylene linker unit as these moieties have been shown to increase planarity and charge-transfer in $\mathrm{D}-\mathrm{A}$ push-pull systems ${ }^{5 b}$ which in turn increases SHG efficiency. ${ }^{16} \mathrm{We}$ have investigated their optical and redox properties and have determined their molecular first hyperpolarisabilities $(\beta)$ using the hyper-Rayleigh scattering (HRS) method which has revealed that these push-pull systems display efficient SHG properties.

\section{Results and discussion}

\section{Synthesis}

The three push-pull flavins (FLA-A-C) have been synthesised from 5-chloro-2-nitroaniline $\mathbf{1}$ through a simple 4-step route in moderate to high yields (Scheme 1). Firstly, compound 1 was acylated to give compound 2 in high yield. The differing donor moieties were then added to this building block using either Suzuki (compounds $\mathbf{3 a}$ and $\mathbf{3 b}$ ) or Sonogashira (compound $\mathbf{3 c}$ ) coupling methodologies. Simultaneous reduction of both the carbonyl- and nitro-moieties with $\mathrm{LiAlH}_{4}$ gave compounds $\mathbf{4 a - c}$. Finally, formation of the flavin moiety was achieved through condensation of $\mathbf{4 a - c}$ with alloxan monohydrate to give the flavin-based dyes FLA-A-C.

\section{Optical properties}

The UV-vis spectra of the three flavin dyes were recorded to determine their optical properties and solvatochromic behaviour, as the latter has been shown to have strong correlation to the ability of compounds to display SHG properties. ${ }^{17}$ Fig. 1 shows that the three dyes have a broad absorption in the visible region. FLA-A and FLA-B show the highest absorbance values at $536 \mathrm{~nm}\left(3066 \mathrm{~L} \mathrm{~mol}^{-1} \mathrm{~cm}^{-1}\right)$ and $517 \mathrm{~nm}$ (4009 $\mathrm{L} \mathrm{mol}^{-1} \mathrm{~cm}^{-1}$ ) $\mathrm{nm}$, respectively. On the other hand, FLA-C shows a highest absorbance at $454 \mathrm{~nm}(2657 \mathrm{~L}$ $\mathrm{mol}^{-1} \mathrm{~cm}^{-1}$ ) $\mathrm{nm}$ and a weaker but longer wavelength absorption at $566 \mathrm{~nm}\left(873 \mathrm{~L} \mathrm{~mol}^{-1} \mathrm{~cm}^{-1}\right)$, which we assign as $\pi$-LUMO and metal-LUMO bands, respectively. ${ }^{18}$ Investigation of the influence solvent polarity has on the absorbance of dyes FLA-A-C (Fig. 2) has revealed that significant solvatochromic behaviour exists for this series of dyes. In accordance with previously reported data for a related push-pull flavin derivative, the $\lambda_{\max }$ values for FLA-A-B did not display a linear correlation with solvent polarity (dielectric constant or $E_{\mathrm{T}}(30)$ ), suggesting that solute-solvent interactions are occuring. ${ }^{12}$ Interestingly, the position of the metal-LUMO absorption bands of FLA-C are in broad correlation with the dielectric constants for the different solvents.

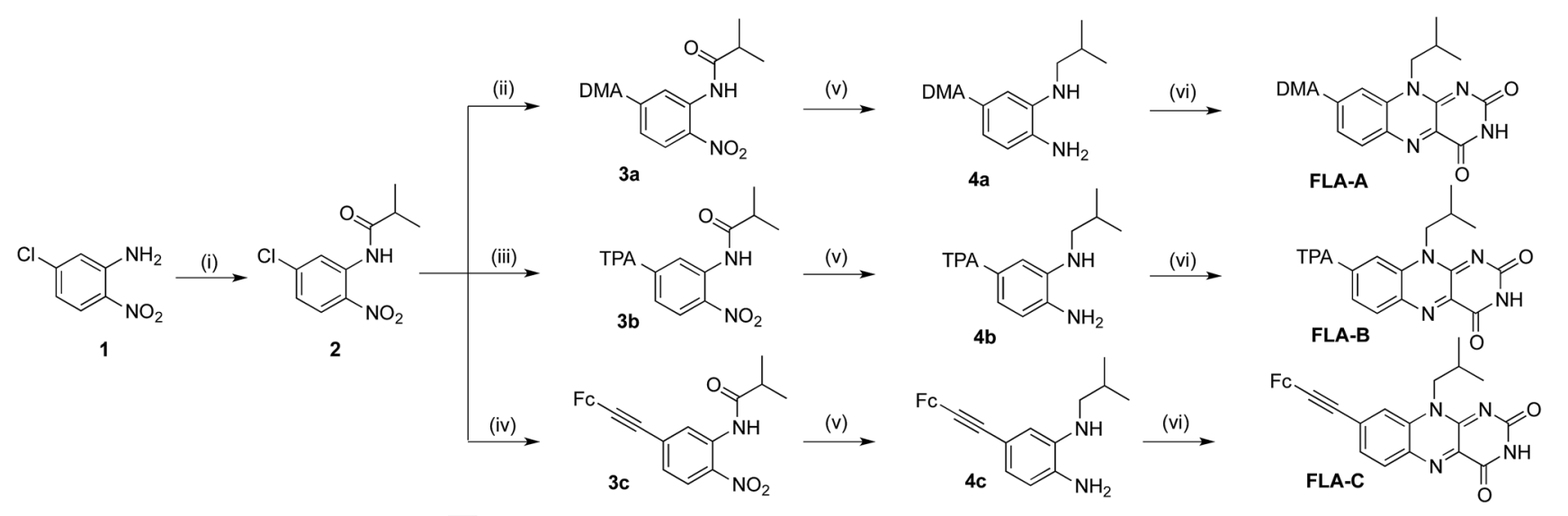

DMA:

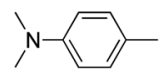

TPA:

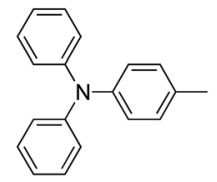

Fc:

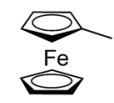

Scheme 1 Synthesis of flavin based dyes. Reagents and conditions: (i) isobutyryl chloride, triethylamine, THF, DMAP, rt, 3 h; (ii) 4-(N,N-dimethylamino)phenylboronic acid, $\mathrm{K}_{2} \mathrm{CO}_{3}, \mathrm{NaCl}, 1,4$-dioxane, reflux, $\mathrm{N}_{2}, 24 \mathrm{~h}$; (iii) 4-(N,N-diphenylamino)phenylboronic acid, $\mathrm{K}_{2} \mathrm{CO}_{3}, \mathrm{NaCl}, 1,4-$ dioxane, reflux, $\mathrm{N}_{2}, 24 \mathrm{~h}$; (iv) ethynylferrocene, 10\% Pd/C, SPhos, $\mathrm{K}_{2} \mathrm{CO}_{3}, \mathrm{DMA}, 110{ }^{\circ} \mathrm{C}, \mathrm{N}_{2}, 2 \mathrm{~h}$; (v) LiAlH 4 , dry-THF, rt, N $2424 \mathrm{~h}$; (vi) alloxan monohydrate, boric anhydride, acetic acid, $\mathrm{rt}, \mathrm{N}_{2}, 24 \mathrm{~h}$. 


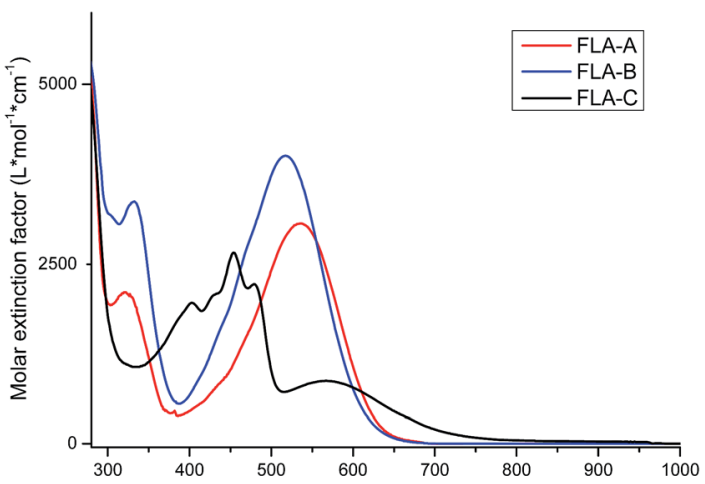

Fig. 1 UV-vis spectra of FLA-A-C $\left(1 \times 10^{-4} M\right.$ in DCM).

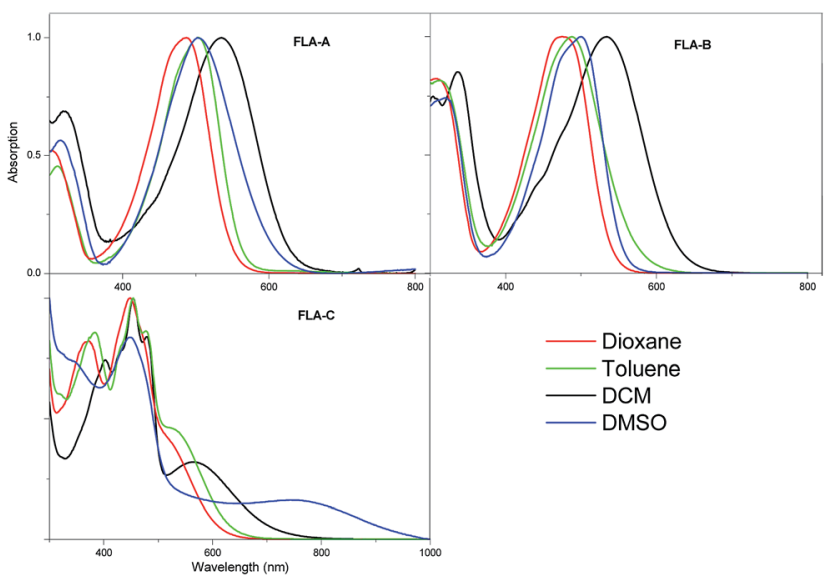

Fig. 2 Normalised UV-vis absorption spectra of FLA-A-C recorded in four different solvents $\left(1 \times 10^{-4} \mathrm{M}\right)$.

\section{Electrochemistry}

The redox properties of the dyes have been investigated using cyclic voltammetry (see ESI, Fig. S4†). Each dye displays a pseudo-reversible oxidation and reduction wave. The differing donor abilities of the $\mathrm{D}$ units play a predictable effect on the electron affinities of the dyes (FLA-A $-3.55 \mathrm{eV}$, FLA-B $-3.88 \mathrm{eV}$, FLA-C $-3.76 \mathrm{eV}),{ }^{15}$ whereas the ionisation potentials of these moieties show a more marked variation (FLA-A $-5.32 \mathrm{eV}$, FLA-B $-5.49 \mathrm{eV}$, FLA-C $-4.99 \mathrm{eV}$ ) in line with their structurally and electronically differing $\mathrm{D}$ moieties.

\section{NLO properties}

The molecular first hyperpolarisabilities $\beta$ of flavin derivatives FLA-A-C were measured by the hyper-Rayleigh scattering (HRS) method ${ }^{19}$ at a fundamental wavelength of $1064 \mathrm{~nm}$ and the data are summarised in Table 1. It is clear that the electronic donor ability of the moieties attached at the position $\mathrm{C}(8)$ of the flavin derivative for compounds FLA-A-C modulates the red-shifted absorption maxima and nonlinearities as anticipated from the donor strengths of the substituents (ferrocenyl- $<4$ - $N, N$-diphenylaniline- $<4-N, N$-dimethylaniline-). These results are not unexpected bearing in mind the Hammett $\sigma_{\mathrm{p}}$ constants of $N, N$ dimethylaniline $\left(\sigma_{\mathrm{p}}=-0.83\right), N, N$-diphenylaniline $\left(\sigma_{\mathrm{p}}=-0.56\right)$ and ferrocenyl $\left(\sigma_{\mathrm{p}}=-0.18\right)$, donor groups ${ }^{20}$ as well as data provided in several earlier studies. ${ }^{6}$ Therefore, 4 - $N, N$-dimethylaniline, being the strongest electron-donor group, gives rise to a higher $\beta$ value for compound FLA-A. ${ }^{21}$ On the other hand, the ferrocenyl derivative FLA-C exhibits the lowest hyperpolarisability $\left(\beta=355 \times 10^{-30}\right.$ esu) compared to FLA-A and $\mathbf{B}(\beta$ $=9550$ and $8660 \times 10^{-30}$ esu, respectively).

\section{Thermal stabilities}

In order to be readily incorporated into efficient optoelectronic devices, organic NLO-phores should exhibit large molecular quadratic hyperpolarisability, good optical transparency and excellent thermal and chemical stabilities. Derivatives that feature alkyl- and aryl-amine moieties as their donor units have been shown to possess these important properties. ${ }^{5 a, 6}$ The thermal stability of chromophores FLA-A-C was studied by thermogravimetric analysis (TGA) and by differential scanning calorimetry (DSC) (see Fig. S1-S3, ESI $\dagger$ ). FLA-A-C exhibit high decomposition temperatures of 312, 329 and $319{ }^{\circ} \mathrm{C}$ respectively. Comparison of the thermal stability of $N, N$-dimethylaniline derivative FLA-A with flavin FLA-B shows that the $N, N$-diphenylaniline-substitution results in an enhanced thermal stability which is in agreement with previous findings. ${ }^{5 a, 6}$

\section{Theoretical calculations}

To further our understanding of the properties of these dyes and establish a comparative computational basis for this series, density functional theory (DFT) calculations were undertaken. The HOMO and LUMO maps of FLA-A-C were computed in

Table 1 UV-vis absorptions, $\beta$ and $\beta_{0}$ values and $T_{d}$ data for flavin derivatives FLA-A-C ${ }^{a}$

\begin{tabular}{lllllll}
\hline Comp. & Donor & $\lambda_{\max }(\mathrm{nm})$ & $\varepsilon_{\max }\left(\mathrm{M}^{-1} \mathrm{~cm}^{-1}\right)$ & $\beta^{b}\left(10^{-30} \mathrm{esu}\right)$ & $\beta_{0}{ }^{c}\left(10^{-30} \mathrm{esu}\right)$ \\
\hline FLA-A & DMA & 487 & 22087 & 9550 & $1220 \pm 120$ \\
FLA-B & TPA & 473 & 25520 & 12720 & 8660 & $1460 \pm 180$ \\
FLA-C & Fc & 449 & - & 355 & $85 \pm 15$ & 309 \\
$p$ NA & - & 352 & 40.1 & 20.1 & 310
\end{tabular}

${ }^{a}$ Experimental first hyperpolarisabilities $\beta$ and spectroscopic data measured in dioxane solutions are reported using the $\mathrm{T}$ convention. ${ }^{b}$ All compounds are transparent at the $1064 \mathrm{~nm}$ fundamental wavelength. ${ }^{c}$ Data corrected for resonance enhancement at $532 \mathrm{~nm}$ using the twolevel model with $\beta_{0}=\beta\left[1-\left(\lambda_{\max } / 1064\right)^{2}\right]\left[1-\left(\lambda_{\max } / 532\right)^{2}\right]$; damping factors not included $1064 \mathrm{~nm} .{ }^{22}{ }^{d}$ Decomposition temperature $\left(T_{\mathrm{d}}\right)$ measured at a heating rate of $10{ }^{\circ} \mathrm{C} \mathrm{min}^{-1}$ under a nitrogen atmosphere, obtained by thermogravimetric analysis (TGA). 

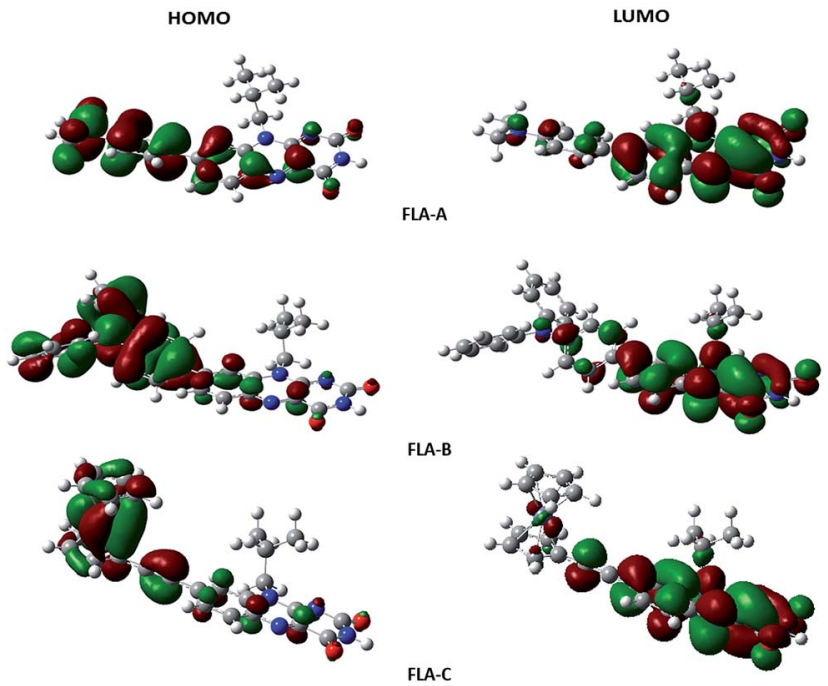

Fig. 3 HOMO and LUMO maps of FLA-A-C.

a polarized solvent continuum of 1,4-dioxane (Fig. 3) and show diffuse and overlapping HOMO and LUMO densities. FLA-A shows the most extensive overlap of HOMO/LUMO densities which is consistent with good CT between the strongest $N, N$ dimethylaniline donor and flavin moieties. The estimated dipole moments for these molecules range between 13 and 17 Debye (in 1,4-dioxane), and follows the same trend as the experimentally determined hyperpolarisabilities (Tables 1 and 2). Interestingly, the magnitude of the calculated hyperpolarisabilities have little correlation with the experimentally determined values for FLA-A and $\mathbf{B}$ in this solvent.

The geometry of each of the dyes were also optimised under differing solvent continua and the dipole moments were calculated. For all dyes the largest calculated dipole moment was obtained in DMSO, with 1,4-dioxane providing the lowest value (Tables 3 and S2, ESI †). Interestingly, for each solvent studied the magnitude of the calculated dipole moment follows the same general trend as the experimentally determined hyperpolarizability values of the dyes. Furthermore, solvent polarity also seems to affect the magnitude of the HOMO more than the LUMO of these compounds (Table S2, ESI $\dagger$ ). Bearing in mind the important relationship between solvatochromism, polarizability and the extrapolation to hyperpolarizability values in second order NLO materials, ${ }^{17}$ the data suggest that for these systems DFT predictions of dipole moment (and its solvent dependency) may offer a better yardstick for designing new analogues with large hyperpolarisability values than their calculated hyperpolarisabilities.
Table 3 Computational study of FLA-A-C in different solvents

\begin{tabular}{lccccc}
\hline Comp. & Donor & $\mu^{a}(\mathrm{D})$ & $\mu^{b}(\mathrm{D})$ & $\mu^{c}(\mathrm{D})$ & $\mu^{d}(\mathrm{D})$ \\
\hline FLA-A & DMA & 17.0152 & 17.2402 & 20.2001 & 21.4030 \\
FLA-B & TPA & 14.3034 & 14.4754 & 16.6393 & 17.4862 \\
FLA-C & Fc & 13.6595 & 13.8190 & 15.7836 & 16.5851 \\
${ }^{a}$ 1,4-Dioxane. ${ }^{b}$ Toluene. ${ }^{c}$ Dichloromethane. ${ }^{d}$ Dimethylsulfoxide.
\end{tabular}

\section{Experimental}

\section{General methods}

All reactions were undertaken under inert atmosphere. Solvents were purified using a Pure Solv ${ }^{\mathrm{TM}}$ solvent purifier system. Reagents were purchased from Sigma Aldrich, and were used without further purification. NMR spectra were obtained with either a Bruker AVIII $400 \mathrm{MHz}$ or a Bruker AVIII $500 \mathrm{MHz}$ spectrometer (relative to TMS). UV-vis spectra were recorded on a Perkin Elmer Lamda 25 instrument. Optical band gaps $\left(E_{\mathrm{G}, \mathrm{OPT}}\right)$ were estimated using the onset of the longest wavelength absorption $(\lambda)$ using $E_{\mathrm{G}, \mathrm{OPT}}(\mathrm{eV})=(1240 / \lambda(\mathrm{nm}))$.

\section{Synthesis}

Compound 2. Isobutyryl chloride (1.84 mL, $17.4 \mathrm{mmol})$ and triethylamine $(2.43 \mathrm{~mL}, 17.4 \mathrm{mmol})$ were added drop-wise to a solution of 5-chloro-2-nitroaniline 1 (2.00 g, $11.6 \mathrm{mmol})$ and 4(dimethylamino)pyridine ( $0.140 \mathrm{~g}, 1.74 \mathrm{mmol})$ dissolved in THF $(100 \mathrm{~mL})$. The mixture was stirred overnight at reflux, and the solvents were then removed under reduced pressure. The crude product was then purified by flash chromatography (petroleum ether/ethyl acetate; $95: 5$ ) and then recrystallised from hot ethanol to yield title compound 2 as yellow needles $(2.69 \mathrm{~g}$, 95\%). Mp 91-92 ${ }^{\circ} \mathrm{C} ; \delta_{\mathrm{H}}\left(500 \mathrm{MHz}, \mathrm{CDCl}_{3}, \mathrm{TMS}\right) 10.56(1 \mathrm{H}, \mathrm{s})$, 8.96 (1H, d, J 2.3), 8.18 (1H, d, J 9.0), 7.13 (1H, dd, J 9.0, 2.3), 2.66 (1H, sept, $J$ 6.9), 1.31 (6H, d, $J 6.9) ; \delta_{\mathrm{C}}\left(125 \mathrm{MHz}, \mathrm{CDCl}_{3}, \mathrm{TMS}\right)$ 176.3, 143.0, 136.3, 134.5, 127.1, 123.4, 121.9, 37.8, 19.4; HRMS $\left(\mathrm{EI}^{+}, \mathrm{m} / \mathrm{z}\right):[\mathrm{M}]^{+}$found, 242.0455; calc. for $\left(\mathrm{C}_{10} \mathrm{H}_{11} \mathrm{ClN}_{2} \mathrm{O}_{3}{ }^{+}\right)$, 242.0458 .

Compound 3a. Compound 2 (1.00 g, $4.13 \mathrm{mmol})$, 4-(dimethylamino) phenylboronic acid (1.36 g, $8.26 \mathrm{mmol}), \mathrm{NaCl}$ $(0.425 \mathrm{~g}, 4.13 \mathrm{mmol})$ and $\mathrm{K}_{2} \mathrm{CO}_{3}(2.28 \mathrm{~g}, 16.5 \mathrm{mmol})$ were dissolved in 1,4-dioxane ( $35 \mathrm{~mL}$ ) and the solution was degassed for 30 minutes with $\mathrm{N}_{2}$. $\mathrm{PdCl}_{2}\left(\mathrm{PPh}_{3}\right)_{2}(68.3 \mathrm{mg}, 83.0 \mu \mathrm{mol})$ was added and the solution was left to stir at reflux. After 24 hours the mixture was allowed to cool to room temperature, poured into water $(200 \mathrm{~mL})$ and extracted with $\mathrm{Et}_{2} \mathrm{O}(4 \times 200 \mathrm{~mL})$. The

Table 2 Computational result summary of FLA-A-C hyperpolarizability calculations

\begin{tabular}{lllllll}
\hline Comp. & Donor & $\mu(\mathrm{D})$ & $\beta_{\text {tot }}\left(10^{-30}\right.$ esu $)$ & $\beta_{\|}\left(10^{-30}\right.$ esu $)$ & HOMO (eV) \\
\hline FLA-A & DMA & 17.01 & 804 & 477 & -5.64 & LUMO (eV) \\
FLA-B & TPA & 14.30 & 1448 & 870 & -5.57 & -3.14 \\
FLA-C & Fc & 13.66 & 615 & 370 & -5.89
\end{tabular}


combined organic extracts were dried over $\mathrm{MgSO}_{4}$, filtered and concentrated under reduce pressure. The crude product was purified by flash chromatography (dichloromethane/petroleum ether; $80: 20$ ) affording $3 \mathrm{a}$ as an orange solid (2.08 g, 65\%). Mp $182-185{ }^{\circ} \mathrm{C} ; \delta_{\mathrm{H}}\left(500 \mathrm{MHz}, \mathrm{CDCl}_{3}, \mathrm{TMS}\right) 10.75(1 \mathrm{H}, \mathrm{s}), 9.12(1 \mathrm{H}, \mathrm{d}$, $J$ 2.0), 8.24 (1H, d, J 8.9), 7.64-7.63 (2H, m), 7.35 (1H, dd, $J$ 8.9, 2.0), 6.77-6.74 (2H, m), 3.02 (6H, s), 2.68 (1H, sept, $J$ 6.9), 1.33 $(6 \mathrm{H}, \mathrm{d}, J 6.9) ; \delta_{\mathrm{C}}\left(125 \mathrm{MHz}, \mathrm{CDCl}_{3}, \mathrm{TMS}\right) 176.5,151.4,149.2$, 136.1, 133.7, 128.5, 126.6, 125.4, 120.1, 118.0, 112.5, 40.4, 37.8, 19.6; HRMS $\left(\mathrm{ESI}^{+}, \mathrm{m} / z\right):[\mathrm{M}+\mathrm{Na}]^{+}$found, 350.1475; calc. for $\left(\mathrm{C}_{18} \mathrm{H}_{21} \mathrm{~N}_{3} \mathrm{NaO}_{3}^{+}\right), 350.1481$.

Compound 3b. Compound 2 (1.00 g, $4.13 \mathrm{mmol})$, 4-(diphenylamino) phenylboronic acid (1.99 g, $5.37 \mathrm{mmol}), \mathrm{NaCl}$ $(0.425 \mathrm{~g}, 4.13 \mathrm{mmol})$ and $\mathrm{K}_{2} \mathrm{CO}_{3}(2.28 \mathrm{~g}, 16.5 \mathrm{mmol})$ were dissolved in 1,4-dioxane ( $35 \mathrm{~mL}$ ) and the solution was degassed for 30 minutes with $\mathrm{N}_{2}$. $\mathrm{PdCl}_{2}\left(\mathrm{PPh}_{3}\right)_{2}(68.3 \mathrm{mg}, 83.0 \mu \mathrm{mol})$ was added and the solution was left to stir at reflux. After 24 hours the mixture was allowed to cool to room temperature, poured into water $(200 \mathrm{~mL})$ and extracted with $\mathrm{Et}_{2} \mathrm{O}(4 \times 200 \mathrm{~mL})$. The combined organic extracts were dried over $\mathrm{MgSO}_{4}$, filtered and concentrated under reduced pressure. The crude product was purified by flash chromatography (dichloromethane/petroleum ether; $80: 20)$ affording $\mathbf{3 b}$ as an orange solid $(2.78 \mathrm{~g}, 67 \%) . \mathrm{Mp}$ 95-98 ${ }^{\circ} \mathrm{C} ; \delta_{\mathrm{H}}\left(400 \mathrm{MHz}, \mathrm{CDCl}_{3}, \mathrm{TMS}\right) 10.67(1 \mathrm{H}, \mathrm{s}), 9.12(1 \mathrm{H}, \mathrm{d}, J$ 2.0), 8.27 (1H, d, $J$ 8.9), 7.57-7.53 (2H, m), 7.35 (1H, dd, $J$ 8.9, 2.0), 7.32-7.27 (4H, m), 7.15-7.06 (8H, m), 2.68 (1H, sept, J 6.9), $1.32(6 \mathrm{H}, \mathrm{d}, J 6.9) ; \delta_{\mathrm{C}}\left(100 \mathrm{MHz}, \mathrm{CDCl}_{3}, \mathrm{TMS}\right)$ 176.5, 149.3, 148.7, 147.3 , 136.0, 134.4, 131.5, 129.6, 128.5, 126.6, 125.2, 123.9, 122.9, 120.8, 119.3, 37.8, 19.6; HRMS $\left(\mathrm{ESI}^{+}, \mathrm{m} / \mathrm{z}\right):[\mathrm{M}+\mathrm{Na}]^{+}$ found, 474.1799; calc. for $\left(\mathrm{C}_{28} \mathrm{H}_{25} \mathrm{~N}_{3} \mathrm{NaO}_{3}{ }^{+}\right)$, 474.1794.

Compound 3c. Compound $2(2.00 \mathrm{~g}, 8.26 \mathrm{mmol})$, ethynylferrocene (2.60 mg, $12.4 \mathrm{mmol}$ ), 10\% Pd/C (0.394 g, 0.372 $\mathrm{mmol}$ ), SPhos (0.153 g, $0.372 \mathrm{mmol}), \mathrm{K}_{2} \mathrm{CO}_{3}(1.71 \mathrm{~g}, 12.4 \mathrm{mmol})$ and dimethylacetamide $(10 \mathrm{~mL})$ were stirred at $110{ }^{\circ} \mathrm{C}$. After 2 hours the dark residue was filtered off, washed with water (500 $\mathrm{mL})$ and then $\mathrm{Et}_{2} \mathrm{O}(2 \times 500 \mathrm{~mL})$. The aqueous extract was washed with $\mathrm{Et}_{2} \mathrm{O}(3 \times 500 \mathrm{~mL})$ and the combined organic extracts were dried over $\mathrm{MgSO}_{4}$, filtered and concentrated under reduced pressure. The product was purified by flash column chromatography (toluene) and isolated as a red solid (2.12 g, 62\%). Mp 129-131 ${ }^{\circ} \mathrm{C}$ (decomposition); $\delta_{\mathrm{H}}\left(500 \mathrm{MHz}, \mathrm{CDCl}_{3}\right.$, TMS) 10.59 (1H, s), 8.97 (1H, d, J 1.8), 8.18 (1H, d, J 8.8), 7.20 $(1 \mathrm{H}, \mathrm{dd}, J 8.8,1.8), 4.54(2 \mathrm{H}, \mathrm{t}, J 1.9), 4.32(2 \mathrm{H}, \mathrm{t}, J 1.9), 4.26(5 \mathrm{H}$, s), $2.68(1 \mathrm{H}, \mathrm{sept}, J 6.9), 1.33(6 \mathrm{H}, \mathrm{d}, J 6.9) ; \delta_{\mathrm{C}}\left(125 \mathrm{MHz} \mathrm{CDCl}_{3}\right.$, TMS) 176.4, 135.5, 134.5, 132.8, 126.1, 125.5, 124.1, 96.3, 85.1, 72.1, 70.3, 69.8, 63.6, 37.8, 19.6; HRMS $\left(\mathrm{EI}^{+}, \mathrm{m} / \mathrm{z}\right):[\mathrm{M}+\mathrm{H}]^{+}$ found, 416.0822; calc. for $\left(\mathrm{C}_{22} \mathrm{H}_{20} \mathrm{FeN}_{2} \mathrm{O}_{3}{ }^{+}\right), 416.0824$.

General procedure for the synthesis of compounds FLA-A-C. To a solution of $\mathbf{3 a - c}$ in dry THF (7 mL mmol $\left.{ }^{-1}\right) \mathrm{LiAlH}_{4}$ (10 eq.) was added portion-wise. The reaction mixture was stirred overnight at room temperature. The mixture was then quenched by the addition of water and further addition of $10 \%$ aqueous $\mathrm{NaOH}$. The resulting precipitate was filtered off and washed thoroughly with $\mathrm{Et}_{2} \mathrm{O}$. The combined organics were dried over $\mathrm{MgSO}_{4}$ and filtered. The solvent was then removed under reduced pressure to give $\mathbf{4 a - c}$ as a crude product, which was used without further purification. Crude $\mathbf{4 a - c}$, alloxan monohydrate ( 1 eq.) and $\mathrm{B}_{2} \mathrm{O}_{3}$ (1.5 eq.) were dissolved in glacial acetic acid $\left(2 \mathrm{~mL} \mathrm{mmol}{ }^{-1}\right)$ and stirred overnight at room temperature. The solvent was then removed under reduced pressure and the crude product was purified by flash chromatography affording FLA-A-C:

\section{FLA-A}

Flash column chromatography (DCM/acetone; 90 : 10) afforded FLA-A as a dark purple red solid $(0.195 \mathrm{~g}, 38 \%)$, from $3 \mathbf{3}(0.408 \mathrm{~g}$, $1.00 \mathrm{mmol}) . \mathrm{Mp}>300{ }^{\circ} \mathrm{C} ; \delta_{\mathrm{H}}\left(400 \mathrm{MHz}, \mathrm{CDCl}_{3}, \mathrm{TMS}\right) 8.40(1 \mathrm{H}$, s), 8.26 (1H, d, $J 8.7), 7.86$ (1H, dd, $J 8.7,1.8), 7.68$ (1H, d, $J 1.8)$, 7.66-7.62 (2H, m), 6.86-6.82 (2H, m), $4.70(2 \mathrm{H}, \mathrm{bs}), 3.09(6 \mathrm{H}, \mathrm{s})$ 2.51(1H, sept, $J$ 6.7), $1.09(6 \mathrm{H}, \mathrm{d}, J 6.7) ; \delta_{\mathrm{C}}\left(100 \mathrm{MHz}, \mathrm{CDCl}_{3}\right.$, TMS) 159.9, 155.3, 151.7, 151.5, 149.4, 135.2, 135.1, 134.1, 133.8, 128.7, 125.5, 125.5, 112.8, 111.1, 51.4, 40.3, 27.8, 20.3; HRMS $\left(\mathrm{NSI}^{+}, m / z\right):[\mathrm{M}+\mathrm{H}]^{+}$found, 390.1922; calc. for $\left(\mathrm{C}_{22} \mathrm{H}_{24} \mathrm{~N}_{5} \mathrm{O}_{2}{ }^{+}\right)$, 390.1925 .

\section{FLA-B}

Flash column chromatography (DCM/acetone; 90 : 10) afforded FLA-B as a dark purple solid (0.132 g, 42\%), from $3 \mathbf{b}(0.275 \mathrm{~g}$, $0.610 \mathrm{mmol}) . \mathrm{Mp}>300{ }^{\circ} \mathrm{C} ; \delta_{\mathrm{H}}\left(400 \mathrm{MHz}, \mathrm{CDCl}_{3}, \mathrm{TMS}\right) 8.37(1 \mathrm{H}$, s), 8.31 (1H, d, J 8.6), 7.85 (1H, dd, J 8.6, 1.7), $7.71(1 \mathrm{H}, \mathrm{s}), 7.58-$ 7.54 (2H, m), 7.36-7.31 (4H, m), 7.20-7.12 (8H, m) 4.70 (2H, bs), $2.51\left(1 \mathrm{H}\right.$, sept, $J$ 6.7), $1.09(6 \mathrm{H}, \mathrm{d}, J 6.7) ; \delta_{\mathrm{C}}\left(100 \mathrm{MHz}, \mathrm{CDCl}_{3}\right.$, TMS) 159.6, 155.1 151.5, 150.0, 148.7, 146.9, 136.0, 135.3, 133.9, 130.8, 129.8, 128.9, 128.5, 125.8, 125.7, 124.5, 122.2, 112.3, 51.5, 27.8, 20.3; HRMS ( $\mathrm{NSI}^{+}, \mathrm{m} / \mathrm{z}$ ): $[\mathrm{M}+\mathrm{H}]^{+}$found, 514.2249; calc. for $\left(\mathrm{C}_{32} \mathrm{H}_{28} \mathrm{~N}_{5} \mathrm{O}_{2}^{+}\right)$, 514.2238.

\section{FLA-C}

Flash column chromatography ( $\mathrm{Et}_{2} \mathrm{O} /$ EtOAc; $\left.4: 1\right)$ afforded FLA$\mathrm{C}$ as a green solid $(0.268 \mathrm{~g}, 34 \%)$, from $3 \mathrm{c}(0.683 \mathrm{~g}, 1.65 \mathrm{mmol})$. $\mathrm{Mp}>300{ }^{\circ} \mathrm{C} ; \delta_{\mathrm{H}}\left(500 \mathrm{MHz}, \mathrm{CDCl}_{3}, \mathrm{TMS}\right) 8.50(1 \mathrm{H}, \mathrm{s}), 8.22(1 \mathrm{H}, \mathrm{d}$, $J$ 8.5), 7.65 (1H, dd, J 8.5, 1.4), 7.62 (1H, d, J 1.4), 4.65 (2H, bs), 4.62 (2H, t,$J 1.9), 4.40$ (2H, t, J 1.9), 4.30 (5H, s), 2.49 (1H, sept, $J$ 6.9), 1.09 (6H, d, J 6.9); $\delta_{\mathrm{C}}\left(125 \mathrm{MHz}, \mathrm{CDCl}_{3}, \mathrm{TMS}\right)$ 170.2, 154.9; 151.5, 135.2, 133.6, 133.4, 132.6, 129.9, 117.4, 113.2, 98.8, 72.3, $70.4,70.3,63.1,51.5,31.1,27.7,20.2 ; \mathrm{HRMS}\left(\mathrm{FAB}^{+}, \mathrm{m} / \mathrm{z}\right):[\mathrm{M}+$ $\mathrm{H}]^{+}$found, 479.1176; calc. for $\left(\mathrm{C}_{26} \mathrm{H}_{23} \mathrm{~N}_{4}{ }^{56} \mathrm{FeO}_{2}{ }^{+}\right), 479.1171$.

\section{Nonlinear optical measurements using the hyper-Rayleigh scattering (HRS) method}

Hyper-Rayleigh scattering (HRS) was used to measure the angleaveraged first hyperpolarisability $\beta$ response of the molecules studied. The experimental set-up for hyper-Rayleigh measurements has previously been described in detail. ${ }^{19 b} \mathrm{~A}$ Q-switched Nd:YAG laser operating at a $10 \mathrm{~Hz}$ repetition rate with approximately $10 \mathrm{~mJ}$ of energy per pulse and a pulse duration (FWHM) close to $12 \mathrm{~ns}$ is used to excite hyper-Rayleigh scattering with an incident wavelength of $1064 \mathrm{~nm}$. The hyper-Rayleigh signal was normalized at each pulse by using a small fraction of the laser pulse to generate a second harmonic signal from a KDP crystal to compensate for fluctuations in the temporal profile of the laser pulses due to longitudinal mode beating. Dioxane was 
used as a solvent, and the $\beta$ values were calibrated using a reference solution of $p$-nitroaniline $(p \mathrm{NA})^{23}$ also dissolved in dioxane at a concentration of $1 \times 10^{-2} \mathrm{~mol} \mathrm{dm}^{-3}$ (external reference method). The hyperpolarisability of $p$ NA dissolved in dioxane is known from EFISH measurements carried out at the same fundamental wavelength. We have chosen to report our values using the so-called $\mathrm{T}$ (Taylor expansion) convention ${ }^{23 b}$ in which the $\beta_{333}$ of $p \mathrm{NA}$ in dioxane at $1064 \mathrm{~nm}$ is $40 \times 10^{-30}$ esu. This value includes a correction factor of 1.88 that accounts for the most recent measurement of the $\mathrm{CCl}_{4}$ hyper-Rayleigh scattering signal which was used as a reference. ${ }^{24}$

All solutions were filtered ( $0.2 \mu \mathrm{m}$ porosity) to avoid spurious signals from suspended impurities. The small hyper Rayleigh signal that arises from dioxane was taken into account. We took particular care to avoid reporting artificially high hyperpolarisabilities due to a possible contamination of the hyperRayleigh signal by molecular fluorescence near $532 \mathrm{~nm}$. Measurements were carried out using two different interference filters with different transmission pass bands centred near the second harmonic at $532 \mathrm{~nm}$ allowing us to estimate and correct for any fluorescence emitted near $532 \mathrm{~nm}$.

\section{TGA/DSC}

Thermogravimetric analysis (TGA) and differential scanning calorimetry (DSC) were performed using a TA Instruments SDT Q-600 series thermal analyser. Gas flow was $100 \mathrm{~mL} \mathrm{~min}^{-1}$. The DSC curves show exotherms as up and endotherms as down.

\section{Theoretical calculations}

Gaussian 09 (ref. 25) was used to estimate solvent dependence and hyperpolarisability factors of the chromophores. The geometry of each dye was initially obtained semi-empirically (PM6). These geometries were then re-optimised at DFT level using the hybrid B3LYP level by employing the $6-31+\mathrm{G}^{* *}$ basis set using polarizable continuum model (keyword: scrf $=$ solvent). Frequency calculations were performed to ensure the absence of negative frequencies. Hyperpolarisability factors were estimated using an incident wavelength of $1064 \mathrm{~nm}$ (keywords: freq = raman, cphf $=$ rdfreq, polar) and with a polarized solvent continuum using dioxane as the solvent (Table 2). ${ }^{26}$

\section{Conclusions}

In conclusion, flavins FLA-A-C were readily synthesised from 5chloro-2-nitroaniline using a simple 4-step synthetic route in moderate to high yields. Evaluation of the first hyperpolarisabilities of FLA-A-C using the hyper-Rayleigh scattering technique showed that derivatives FLA-A and FLA-B bearing stronger donor groups exhibit the higher hyperpolarisabilities $(\beta$ $=8660-9550 \times 10^{-30} \mathrm{esu}$ ) and higher thermal stabilities thereby indicating their potential future application in NLO devices. The convenient synthesis, good thermal stability and efficient SHG properties of this class of flavin derivatives suggest that related molecules may prove to be interesting candidates for further development. Moreover, the well-documented ability to accurately predict the physical properties of flavins using linear free energy relationships and, as we have shown here DFT calculations, will help ensure that push-pull flavin derivatives of this type, once embedded into acentric structures, ${ }^{27}$ will become an important class of NLO materials with predictable properties.

\section{Acknowledgements}

GC thanks EPSRC (EP/E036244/1). VR thanks the NSF (CHE1307021). NM thanks the Ministry of Higher Education and Scientific Research of Iraq and the University of Kirkuk. MMR thanks the Funds provided by FCT through the Chemistry Research Centre of the University of Minho (Ref. UID/QUI/ 00686/2013 and UID/QUI/0686/2016) and a PhD grant to S. S. M. Fernandes (SFRH/BD/87786/2012). The NMR spectrometer Bruker Avance III 400 is part of the National NMR Network and was purchased within the framework of the National Program for Scientific Re-equipment, with funds from FCT.

\section{References}

1 D. S. Chemla and J. Zyss, Nonlinear Optical Properties of Organic Molecules and Crystals, Academic Press, New York, 1987.

2 F. Meyers, S. R. Marder and J. W. Perry, in Chemistry of Advanced Materials: An Overview, ed. L. V. Interrante and M. J. Hampden-Smith, Wiley-VCH, New York, 1998, pp. 207269.

3 (a) P. N. Prasad and D. J. Williams, in Introduction to Nonlinear Optical Effects in Molecules and Polymers, ed. J. Klafter and J. M. Drake, Wiley, New York, 1991, pp. 132174; (b) H. S. Nalwa and S. Miyata, Nonlinear Optics of Organic Molecules and Polymers, CRC Press, New York, 1997; (c) L. R. Dalton, P. A. Sullivan, D. Bale, B. Olbricht, J. Davies, S. Benight, I. Kosilkin, B. H. Robinson, B. E. Eichinger and A. K. Y. Jen, in Organic Thin Films for Photonic Applications, ed. W. N. Herman, S. R. Flom and S. H. Foulger, American Chemical Society, Washington DC, 2010, vol. 1039, ch. 2, pp. 13-33; (d) T. Verbiest, S. Houbrechts, M. Kauranen, K. Clays and A. Persoons, J. Mater. Chem., 1997, 7, 2175-2189; (e) H. S. Nalwa and S. Miyata, Nonlinear Optics of Organic Molecules and Polymers, CRC Press, New York, 1997.

4 (a) J. Zyss, Molecular Nonlinear Optics: Materials, Physics, Devices, Academic Press, Boston, 1994; (b) G. S. He, L.-S. Tan, Q. Zheng and P. N. Prasad, Chem. Rev., 2008, 108, 1245-1330; (c) M. M. M. Raposo, in The Encyclopedia of colour science and technology, ed. R. Luo, Springer, New York, 2014, pp. 1-14.

5 (a) L. R. Dalton, P. A. Sullivan and D. H. Bale, Chem. Rev., 2010, 110, 25-55; (b) F. Bureš, RSC Adv., 2014, 4, 5882658851.

6 (a) F. Liu, H. Xiao, Y. Yang, H. Wang, H. Zhang, J. Liu, S. Bo, Z. Zhen, X. Liu and L. Qiu, Dyes Pigm., 2016, 130, 138-147; (b) J. Wu, B. A. Wilson, D. W. J. Smith and S. O. Nielsen, J. Mater. Chem. C, 2014, 2, 2591-2599; (c) Y.-J. Cheng, J. Luo, S. Hau, D. H. Bale, T.-D. Kim, Z. Shi, D. B. Lao, N. M. Tucker, Y. Tian, L. R. Dalton, P. J. Reid and A. K.-Y. Jen, Chem. 
Mater., 2007, 19, 1154-1163; (d) S. Suresh, H. Zengin, B. K. Spraul, T. Sassa, T. Wada and D. W. Smith, Tetrahedron Lett., 2005, 46, 3913-3916; (e) C. Cai, I. Liakatas, M.-S. Wong, M. Bosch, C. Bosshard, P. Günter, S. Concilio, N. Tirelli and U. W. Suter, Org. Lett., 1999, 1, 1847-1849.

7 N. J. Long, Angew. Chem., Int. Ed., 1995, 34, 21-38.

8 For representative examples see: (a) M. L. H. Green, S. R. Marder, M. E. Thompson, J. A. Bandy, D. Bloor, P. V. Kolinsky and R. J. Jones, Nature, 1987, 330, 360-362; (b) I. Asselberghs, K. Clays, A. Persoons, A. M. McDonagh, M. D. Ward and J. A. McCleverty, Chem. Phys. Lett., 2003, 368, 408-411; (c) J. Chiffre, F. Averseng, G. G. A. Balavoine, J.-C. Daran, G. Iftime, P. G. Lacroix, E. Manoury and K. Nakatani, Eur. J. Inorg. Chem., 2001, 9, 2221-2226; (d) N. Tsuboya, R. Hamasaki, M. Ito, M. Mitsuishi, T. Miyashita and Y. Yumansoto, J. Mater. Chem., 2003, 13, 511-513; (e) Y. Liao, B. E. Eichinger, K. A. Firestone, M. Haller, J.-D. Luo, W. Kaminsky, J. B. Benedict, P. J. Reid, A. K.-Y. Jen, L. R. Dalton and B. H. Robinson, J. Am. Chem. Soc., 2005, 127, 2758-2766; $(f)$ C. Arbez-Gindre, B. R. Steele, G. A. Heropoulos, C. G. Screttas, J.-E. Communal, W. J. Blau and I. Ledoux-Rak, J. Organomet. Chem., 2005, 690, 1620-1626; $(g)$ I. Janowska, J. Zakrzewski, K. Nakatani, M. Palusiak, M. Walak and H. Scholl, J. Organomet. Chem., 2006, 691, 323-330; $(h)$ T. L. Kinnibrugh, S. Salman, Y. A. Getmanenko, V. Coropceanu, W. W. Porter III, T. V. Timofeeva, A. J. Matzger, J.-L. Brédas, S. R. Marder and S. Barlow, Organometallics, 2009, 28, 1350-1357; (i) B. J. Coe, S. P. Foxon, M. Helliwell, D. Rusanova, B. S. Brunschwig, K. Clays, G. Depotter, M. Nyk, M. Samoc, D. Wawrzynczyk, J. Garín and J. Orduna, Chem.-Eur. J., 2013, 19, 6613-6629; (j) M. Zaarour, A. Singh, C. Latouche, J. A. G. Williams, I. Ledoux-Rak, J. Zyss, A. Boucekkine, H. Le Bozec, V. Guerchais, C. Dragonetti, A. Colombo, D. Roberto and A. Valore, Inorg. Chem., 2013, 52, 7987-7994; (k) S. Kaur, S. Dhoun, G. Depotter, P. Kaur, K. Clays and K. Singh, RSC $A d v .$, 2015, 5, 84643-84656; (l) L. E. R. Buckley, B. J. Coe, D. Rusanova, S. Sánchez, M. Jirásek, V. D. Joshi, J. Vávra, D. Khobragade, L. Pospíšil, Š. Ramešová, I. Císařová, D. Šaman, R. Pohl, K. Clays, N. V. Steerteghem, B. S. Brunschwig and F. Teplý, Dalton Trans., 2017, 46, 1052-1064.

9 (a) I. D. L. Albert, T. J. Marks and M. A. Ratner, J. Am. Chem. Soc., 1997, 119, 6575-6582; (b) S. Bradamante, A. Facchetti and G. A. Pagani, J. Phys. Org. Chem., 1997, 10, 514-524; (c) M. M. M. Raposo, A. M. R. C. Sousa, G. Kirsch, F. Ferreira, M. Belsley, E. Matos Gomes and A. M. C. Fonseca, Org. Lett., 2006, 8, 3681-3684; (d) R. M. F. Batista, S. P. G. Costa, E. L. Malheiro, M. Belsley and M. M. M. Raposo, Tetrahedron, 2007, 63, 4258-4265; (e) J. Pina, S. Seixas de Melo, R. M. F. Batista, S. P. G. Costa and M. M. M. Raposo, Phys. Chem. Chem. Phys., 2010, 12, 9719-9725; (f) M. C. R. Castro, M. Belsley, A. M. C. Fonseca and M. M. M. Raposo, Tetrahedron, 2012, 68, 8147-8155; (g) M. C. R. Castro, M. Belsley and M. M. M. Raposo, Dyes
Pigm., 2016, 128, 89-95; (h) M. C. R. Castro, M. Belsley and M. M. M. Raposo, Dyes Pigm., 2016, 131, 333-335.

10 C. T. Walsh and T. A. Wencewicz, Nat. Prod. Rep., 2013, 30, 175-200.

11 V. Nandwana, I. D. W. Samuel, G. Cooke and V. M. Rotello, Acc. Chem. Res., 2013, 46, 1000-1009.

12 B. J. Jordan, M. A. Pollier, Y. Ofir, S. Joubanian, J. G. Mehtala, C. Sinkel, S. T. Caldwell, A. Kennedy, G. Rabani, G. Cooke and V. M. Rotello, Chem. Commun., 2008, 1653-1655.

13 (a) X. Yu, S. Eymur, V. Singh, B. Yang, M. Tonga, A. Bheemaraju, G. Cooke, C. Subramani, D. Venkataraman, R. J. Stanley and V. M. Rotello, Phys. Chem. Chem. Phys., 2012, 14, 6749-6754; (b) M. Murakami, K. Ohkubo and S. Fukuzumi, Chem.-Eur. J., 2010, 16, 7820-7832.

14 R. F. Pauszek, G. Kodali, S. T. Caldwell, B. Fitzpatrick, N. Y. Zainalabdeen, G. Cooke, V. M. Rotello and R. J. Stanley, J. Phys. Chem. B, 2013, 117, 15684-15694.

15 Y.-M. Legrand, M. Gray, G. Cooke and V. M. Rotello, J. Am. Chem. Soc., 2003, 125, 15789-15795.

16 A. P. Menezes, A. Jayarama and S. W. Ng, J. Mol. Struct., 2015, 1088, 85-94.

17 (a) M. M. Oliva, J. Casado, M. M. M. Raposo, A. M. C. Fonseca, H. Hartmann, V. Hernández and J. T. L. Navarrete, J. Org. Chem., 2006, 71, 7509-7520; (b) S. P. G. Costa, R. M. F. Batista, P. Cardoso, M. Belsley and M. M. M. Raposo, Eur. J. Org. Chem., 2006, 3938-3946; (c) S. Kothavale and N. Sekar, Dyes Pigm., 2017, 136, 31-45.

18 C. Coluccini, A. K. Sharma, D. Merli, D. V. Griend, B. Mannucci and D. Pasini, Dalton Trans., 2011, 40, 1171911725.

19 (a) K. Clays and A. Persoons, Rev. Sci. Instrum., 1992, 63, 3285-3289; (b) C. Herbivo, A. Comel, G. Kirsch, A. M. C. Fonseca, M. Belsley and M. M. M. Raposo, Dyes Pigm., 2010, 86, 217-226.

20 C. Hansch, A. Leo and R. W. Taft, Chem. Rev., 1991, 91, 165195.

21 C. Coluccini, A. K. Sharma, M. Caricato, A. Sironi, E. Cariati, S. Righetto, E. Tordin, C. Botta, A. Forni and D. Pasini, Phys. Chem. Chem. Phys., 2013, 15, 1666-1674.

22 (a) J. L. Oudar, J. Chem. Phys., 1977, 67, 446-457; (b) J. L. Oudar and D. S. Chemla, J. Chem. Phys., 1977, 66, 2664-2668; (c) J. Zyss and J. L. Oudar, Phys. Rev. A, 1982, 26, 2016-2027.

23 (a) P. Kaatz and D. P. Shelton, J. Chem. Phys., 1996, 105, 3918-3929; (b) H. Reis, J. Chem. Phys., 2006, 125, 014506.

24 R. D. Pyatt and D. P. Shelton, J. Chem. Phys., 2001, 114, 99389946.

25 M. J. Frisch, G. W. Trucks, H. B. Schlegel, G. E. Scuseria, M. A. Robb, J. R. Cheeseman, G. Scalmani, V. Barone, G. A. Petersson, H. Nakatsuji, X. Li, M. Caricato, A. Marenich, J. Bloino, B. G. Janesko, R. Gomperts, B. Mennucci, H. P. Hratchian, J. V. Ortiz, A. F. Izmaylov, J. L. Sonnenberg, D. Williams-Young, F. Ding, F. Lipparini, F. Egidi, J. Goings, B. Peng, A. Petrone, T. Henderson, D. Ranasinghe, V. G. Zakrzewski, J. Gao, N. Rega, G. Zheng, W. Liang, M. Hada, M. Ehara, K. Toyota, R. Fukuda, J. Hasegawa, M. Ishida, T. Nakajima, Y. Honda, 
O. Kitao, H. Nakai, T. Vreven, K. Throssell, J. A. Montgomery Jr, J. E. Peralta, F. Ogliaro, M. Bearpark, J. J. Heyd, E. Brothers, K. N. Kudin, V. N. Staroverov, T. Keith, R. Kobayashi, J. Normand, K. Raghavachari, A. Rendell, J. C. Burant, S. S. Iyengar, J. Tomasi, M. Cossi, J. M. Millam, M. Klene, C. Adamo, R. Cammi, J. W. Ochterski, R. L. Martin, K. Morokuma, O. Farkas, J. B. Foresman and D. J. Fox, Gaussian 09, Revision A.02, Gaussian, Inc., Wallingford CT, 2016.

26 K. S. Thanthiriwatte and K. M. N. de Silva, J. Mol. Struct.: THEOCHEM, 2002, 617, 169-175.
27 (a) S.-S. Sun and L. R. Dalton, Introduction to Organic Electronic and Optoelectronic Materials and Devices, CRC Press, $2^{\text {nd }}$ revised edn, 2016; (b) E. Kang, T. Bu, P. Jin, J. Sun, Y. Yang and J. Shen, Langmuir, 2007, 23, 7594-7601; (c) Y. Liao, S. Bhattacharjee, K. A. Firestone, B. E. Eichinger, R. Paranji, C. A. Anderson, B. H. Robinson, P. J. Reid and L. R. Dalton, J. Am. Chem. Soc., 2006, 128, 6847-6853; (d) A. Facchetti, E. Annoni, L. Beverina, M. Morone, P. Zhu, T. J. Marks and G. A. Pagani, Nat. Mater., 2004, 3, 910-917; (e) J. Yu, Y. Cui, C. Wu, Y. Yang, Z. Wang, M. O'Keefe, B. Chen and Q. Qian, Angew. Chem., Int. Ed., 2012, 51, 10542-10545. 